\title{
Water Network Design Using a Multiobjective Real Options Framework
}

\author{
João Marques, ${ }^{1}$ Maria Cunha, ${ }^{1}$ Dragan Savić, ${ }^{2}$ and Orazio Giustolisii ${ }^{3}$ \\ ${ }^{1}$ Marine and Environmental Sciences Centre (MARE), Department of Civil Engineering, University of Coimbra, Coimbra, Portugal \\ ${ }^{2}$ Centre for Water Systems, School of Engineering, Computing and Mathematics, University of Exeter, Exeter, UK \\ ${ }^{3}$ Department of Civil Engineering and Architecture, Technical University of Bari, Bari, Italy \\ Correspondence should be addressed to João Marques; jmarques@dec.uc.pt
}

Received 13 October 2016; Accepted 4 January 2017; Published 31 January 2017

Academic Editor: Hamed Fazlollahtabar

Copyright (C) 2017 João Marques et al. This is an open access article distributed under the Creative Commons Attribution License, which permits unrestricted use, distribution, and reproduction in any medium, provided the original work is properly cited.

\begin{abstract}
Water distribution networks (WDNs) are an essential element of urban infrastructure. To achieve a good level of performance, the traditional design of WDNs based on expected future conditions should be replaced by a flexible design, using real options (ROs), that accounts for uncertainty by taking a broader view of possible future options. This work proposes a multiobjective ROs framework that sets out to reduce costs, minimize hydraulic pressure deficiency, and a third objective for minimizing carbon emissions. A multiobjective simulated annealing algorithm is used to identify the Pareto-optimal solutions, thus enabling a tradeoff analysis between solutions. These trade-offs show that a low pressure deficit solution is achieved by increasing investment at a much faster rate after a certain pressure deficit threshold $(60 \mathrm{~m})$. Also, the pressure deficits can only be reduced by increasing carbon emissions. Finally, this work also emphasizes the importance of including carbon emissions as a specific objective by comparing the results of the proposed model and another one that did not cover the environmental objective. The results show that it is possible to reduce $\mathrm{CO}_{2}$ for the same level of capital expenditure or the same level of network pressure deficits if carbon emissions are minimized in the optimization process.
\end{abstract}

\section{Introduction}

Water distribution networks (WDNs) are an important element of urban infrastructure whose purpose is to deliver water of appropriate quality and quantity to users without major interruptions. People normally have high expectations regarding the level of service provided by water utilities. Failure should be prevented at all costs, and so water companies wish to maintain high performance and quality standards. The proper functioning of these infrastructure elements under normal and abnormal operation conditions can only be guaranteed if uncertainty is proactively taken into account at the planning stage. In the traditional design of WDNs, a fixed design is determined by assuming a deterministic projected future demand. This can lead to the underdesign or overdesign of WDNs. With this shortcoming in mind, the paradigm has to be changed by using real options (ROs) to achieve a flexible design.
Myers [1] was the first to propose ROs and mention using option pricing theory to value nonfinancial or "real" investments with learning and flexibility. A number of studies have been published where the ROs concepts have been applied in various fields, such as industrial processes [2], energy systems [3], mining projects [4], flooding problems [5], and maritime costal defences [6]. For the design of WDNs, ROs have been explored by Huang et al. [7], who use ROs accounting for future demand uncertainty in a singleobjective approach. Basupi and Kapelan [8, 9], also considering demand uncertainty, propose a flexible design using a multiobjective optimization model with two objectives, cost minimization and the maximization of end resilience. The intervention plans set out in these papers [7-9] are defined in stages but they do not allow for different expansion areas for the WDN during the planning horizon. Here we aim to introduce a different analysis by proposing a ROs approach that considers expansion scenarios of the network at different 
time phases and by taking into account environmental concerns using a multiobjective optimization model with three objectives. In Marques et al. [10], the carbon emissions were included in the costs objective. This is not satisfactory as carbon prices are very volatile and the consideration of a fixed value for the entire planning horizon of the network can lead to the impact of carbon emissions being misrepresented. Furthermore, there are aspects of pipe manufacturing and energy production where, in some cases, the carbon emissions related to the industrial process are already included in the final price of the product and thus should not be duplicated in the model. To overcome the shortcomings of past works in which carbon emissions are monetized and minimized within a cost minimization function [10], we propose to evaluate the impact of carbon emissions in a separate objective. Additionally, some comparisons are made to identify the advantages of considering these environmental concerns in the ROs approach.

The initial attempts to achieve optimal design and operation of WDNs focused on a single-objective strategy, that is, solving a least-cost optimization problem whose primary decision variables were the pipe diameters. One of the first attempts was made by Alperovits and Shamir [11]. However, a number of investigators have noted that, from a technical standpoint, the design of WDNs could be improved by using a multiobjective strategy. That approach allows the best trade-offs to be identified among different objectives, such as cost, reliability and environmental issues. As explained by Savic [12], single-objective optimization approaches have a number of limitations and a multiobjective technique is proposed to avoid these difficulties. Therefore, this work presents a multiobjective optimization model that includes the traditional objectives of minimizing costs and improving hydraulic performance, along with a third objective in the optimization process to explicitly take into account environmental concerns by minimizing the carbon emissions. Some studies even include environmental impacts in the water infrastructure planning, e.g., Herstein et al. [13], who present an index-based method to assess the environmental impact of WDN and D'Ercole et al. [14] who optimize the WDN performance by taking environmental impacts into account. However, there is a gap in the literature with respect to handling environmental issues in a multiphase design scheme through the use of real options (ROs) to achieve a flexible design. Our work intends to fill this gap.

This work presents an optimization method for the design and operation of WDNs that implements a multiphase strategy to achieve a flexible design by taking uncertainty into consideration when planning short- to long-term investments. The multiphase design of WDNs can be defined as design that is carried out in phases using small time horizons at each phase (rather than considering the full planning horizon). This enables decision makers to actively manage the configuration of the network and easily adapt it to new situations. A multiphase design is more cost effective for a long planning horizon than a single-phase design because the construction costs are incurred progressively over time and not all at once (year zero of the planning horizon), which is the case for a single phase. Deferring costs saves money.
Furthermore, multiphase design makes it possible to adjust the WDN's capacity if conditions turn out to be different from those projected. The traditional single-phase solutions, however, can result in a system that may need upgrading from time to time or require excessive initial investment in capacity that may not be required for a long time.

The rest of the paper is organized as follows: Section 2 sets out the multiobjective optimization algorithm, followed in Section 3 by the multiobjective decision model established according to the ROs approach. Then a detailed description of the case study is presented in Section 4, including the future scenarios options, after which the results are given in Section 5 and some comparisons drawn. Section 6 lists some conclusions.

\section{Multiobjective Simulated Annealing}

The multiobjective optimization problem is solved by a simulated annealing heuristic [15]. Simulated annealing is a popular search algorithm based on an analogy with the physical process of cooling a material in a heat bath [16]. Annealing is the process of heating a solid until its melting temperature and then slowly reducing the temperature. If the cooling process is sufficiently slow the process forms a new material with a well-organized structure and the lowest internal energy state. The notion of slowly decreasing the temperature is adapted in the simulated annealing algorithm to guide the optimization process by slowly reducing the probability of accepting worse solutions (those that have worse values of the objectives) during the exploration of the solution space. The possibility of accepting worse solutions is a crucial property that allows the algorithm to escape from local optimums and enables a more widespread search. The algorithm comes to an end when the temperature parameter achieves the desired level.

A literature review shows that simulated annealing has been used in various fields, including regional wastewater system planning by Zeferino et al. [17] and groundwater monitoring networks by Nunes et al. [18], where it performed well. Cunha and Sousa [19] and Reca et al. [20, 21] have demonstrated the successful use of simulated annealing in WDNs for single-objective optimization models. In a previous work by Marques et al. [10], a simulated annealing algorithm was proposed and used in a two-objective optimization model for the design of WDNs. A three-objective optimization model (the type of model proposed here) is more complex than a two-objective model, because the search for the Paretooptimal front becomes harder due to the increase of the number of incomparable solutions and also because it is more difficult to classify the dominance relationship between solutions to guide the search.

The multiobjective simulated annealing algorithm is used in a three-objective model to search for the Pareto-optimal front by generating potential solutions in the solution space and evaluating the domination status between new solutions and solutions that have already been found. The domination status is represented schematically by Figure 1 between two solutions "a" and "b" and is computed by multiplying the change in values (if this is a nonzero value) of the objectives 


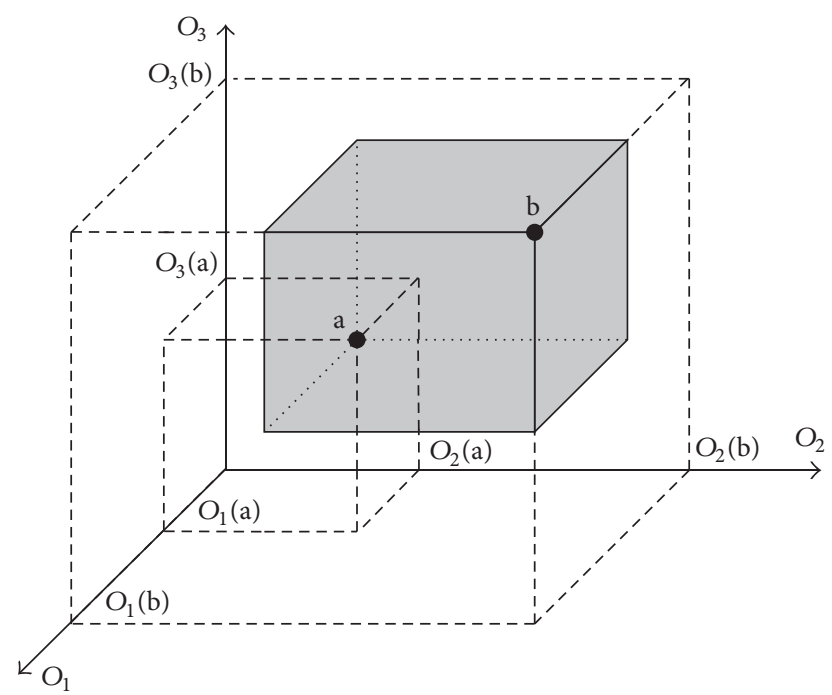

FIGURE 1: Dominance between solutions "a" and "b."

$(\mathrm{O} 1, \mathrm{O} 2$, and $\mathrm{O} 3)$. In a three-objective optimization problem, the domination is given by a parallelepiped volume, as shown in Figure 1, where the lengths of the edges are given by the change in values of the three objectives. If these differences are large, the volume or dominance between solutions is high. But if the volume is small, so is the dominance of the solutions.

Depending on the domination status, the potential solutions are accepted or rejected according to the Metropolis criterion [16], which guides the optimization process until the stop criterion is met. In addition, the ROs approach divides the planning horizon into design phases where different decisions are taken. These multiple design phases increase the complexity of the problem. Furthermore, to easily explore the solutions provided by the optimization model, a visualization tool AEROVIS [22] is used to plot the Pareto solutions.

\section{Multiobjective Optimization Model Formulation}

3.1. Decision Variables. The approach described here aims to define the flexible design for WDNs by achieving the minimization of three objectives: investment and operation costs, pressure deficit, and carbon emissions. The decision variables are the commercial pipe diameters of the WDN. The flexible design strategy determines the value of the decision variables for the first phase and also for all the future decision options that arise from all the possible decision paths (corresponding to different scenarios of expansion of the network for different time periods). However, the values of the decision variables that are determined for the first phase are effectively the ones that are required now, and therefore it is very important to ensure that these decisions are flexible enough to cope with the network conditions in the next phases. The values of the decision variables for the future time periods (phases) can be adjusted as new information arises.
3.2. Objective Functions. We formulated the multiobjective optimization model to minimize costs, pressure deficits, and carbon emissions. These three objectives are minimized simultaneously to allow identifying the major trade-offs between them and are represented in the following expressions:

$$
\begin{aligned}
& \mathrm{O} 1=\min (\mathrm{Ci}+\mathrm{Cf}) \\
& \mathrm{O} 2=\min (\mathrm{HPD}) \\
& \mathrm{O} 3=\min \left(\text { tonCO }_{2}\right),
\end{aligned}
$$

where $\mathrm{Ci}$ is cost of the initial solution to be implemented in the first period (USD); Cf are future costs (USD); HPD are hydraulic pressure deficits $(\mathrm{m})$; and ton $\mathrm{CO}_{2}$ are tonnes of $\mathrm{CO}_{2}$ emitted (ton).

Equation (1), representing the first objective, is given as the sum of the initial solution costs to be implemented in the first period or phase and the future costs for the planning horizon. The term Ci computes the cost for the first period and is calculated by

$$
\mathrm{Ci}=\sum_{i=1}^{\mathrm{NPI}}\left(\mathrm{Cpipe}_{i, 1}\right)+\sum_{j=1}^{\mathrm{NPU}}\left(\mathrm{Cps}_{j, 1}\right)+\sum_{d=1}^{\mathrm{NDC}} \mathrm{Ce}_{d, 1},
$$

where NPI is number of pipes in the network; Cpipe $_{i, 1}$ is cost of pipe $i$ in period $t=1$; NPU is number of pumps in the network; $\mathrm{Cps}_{j, 1}$ is pumping station costs of pump $j$ in the period $t=1$; NDC is number of demand conditions considered for the design; and $\mathrm{Ce}_{d, 1}$ is present value cost of energy (computed for the time period) under demand condition $d$ in period $t=1$.

Summing the cost of pipes, the cost of pumps, and the present value of the energy cost we get the total cost for the solution of $t=1$. The other term of the objective function $O 1$ in (1) represents the future cost of pipes, pumps, and energy of all the scenarios. These costs are weighted by the corresponding probability of each scenario of expansion as showed in

$$
\mathrm{Cf}=\sum_{s=1}^{\mathrm{NSNTI}} \sum_{t=2}\left(\text { Cfuture }_{t, s} \cdot \prod_{\mathrm{nt}=2}^{t} \operatorname{prob}_{\mathrm{nt}, s}\right),
$$

where NS is number of scenarios; NTI is number of periods into which the planning horizon is divided; Cfuture $t_{t, s}$ is cost of future designs in scenario $s$ for period $t$; and $\operatorname{prob}_{\mathrm{nt}, s}$ is probability of $s$ in period nt (nt represents the number of time periods, from the second to the one under analysis).

The future costs are computed, for each path, by summing all costs incurred in each period, starting from the second time period. In each future option the costs are computed by multiplying the cost of each design option by the probability of taking that option. The term Cfuture ${ }_{t, s}$ is computed in (6), 
for all future options established after $t=1$ (the costs for the first period are already calculated by $\mathrm{Ci}$ ).

$$
\begin{gathered}
\text { Cfuture }_{t, s} \\
=\left[\sum_{i=1}^{\mathrm{NPI}} \mathrm{Cpipe}_{i, t, s}+\sum_{j=1}^{\mathrm{NPU}}\left(\mathrm{Cps}_{j, t, s}\right)+\sum_{d=1}^{\mathrm{NDC}}\left(\mathrm{Ce}_{d, t, s}\right)\right] \\
\cdot \frac{1}{(1+\mathrm{IR})^{Y_{t}}}, \quad \forall t \in \mathrm{NTI} ; \forall s \in \mathrm{NS},
\end{gathered}
$$

where Cpipe i,t,s $_{\text {is }}$ cost of pipe $i$ installed in period $t$ and in scenario $s$; $\mathrm{Cps}_{j, t, s}$ is pumping station costs of pump $j$ installed in period $t$ and in scenario $s$; $\mathrm{Ce}_{d, t, s}$ is present value cost of energy (updated for the first year of the time period $t$ ) under demand condition $d$ for period $t$ and in scenario $s$; IR is annual interest rate for updating cost; and $Y_{t}$ is year when costs will be incurred for period $t$.

The future costs are computed by a sum of 3 terms: the first term computes the cost of pipes, the second term computes the cost of installing pumps, and the last term computes the energy cost of pump operation in the time period. The present value of these costs is then computed for the year when the costs will be incurred. Summing the terms $\mathrm{Ci}$ with $\mathrm{Cf}$ in (1), the total cost for the whole planning horizon is determined. The uncertainty of future network expansion is taken into account, according to a decision tree, where each path has its own probability.

The second objective function (O2), given in (2), aims to minimize the total pressure deficits, considering all possible future options that can be taken for the planning horizon. This is computed by summing the node pressure deficits for the different possible scenarios according to

$$
\mathrm{HPD}=\sum_{s=1}^{\mathrm{NS}} \sum_{t=2}^{\mathrm{NTI}} \sum_{d=1}^{\mathrm{NDC}} \sum_{n=1}^{\mathrm{NN}} \max \left\{0 ;\left(\mathrm{Pdm}_{n, d}-P_{n, d, t, s}\right)\right\},
$$

where $\mathrm{NN}$ is number of nodes; $\mathrm{Pdm}_{n, d}$ is minimum desirable pressure at node $n$ for demand condition $d$; and $P_{n, d, t, s}$ is pressure at node $n$ at demand condition $d$ for time period $t$ and in scenario $s$.

Equation (7) computes the pressure deficits for all scenarios, all time periods, after $t=1$, for all the demand conditions, and for all the nodes. For $t=1$, nodal pressures have to be totally satisfied (i.e., nodal pressures equal to or higher than minimum desirable pressures). This sum can be used as a measure of the network performance over the entire planning horizon.

Finally, the third objective (O3) in (3) includes the minimization of carbon emissions due to installation and operation of the WDN and is defined in (8). The carbon emissions are evaluated by considering the whole life cycle, including the extraction of raw materials, transport, manufacture, assembly, installation, disassembly, demolition and/or decomposition [23]. The carbon emissions from the energy used during the network's operation, mainly by pumping stations, are also computed. We do not consider the other elements of the network, for simplification purposes.

$$
\begin{aligned}
& \text { tonCO } \mathrm{CO}_{2}=\sum_{i=1}^{\mathrm{NPI}}\left(\mathrm{CO}_{2} \mathrm{pipe}_{i, 1}\right)+\sum_{d=1}^{\mathrm{NDC}}\left(\mathrm{CO}_{2} \mathrm{Ce}_{d, 1}\right) \\
& +\sum_{s=1}^{\mathrm{NS}} \sum_{t=2}^{\mathrm{NTI}}\left\{\left[\sum_{i=1}^{\mathrm{NPI}}\left(\mathrm{CO}_{2} \mathrm{pipe}_{i, t, s}\right)+\sum_{d=1}^{\mathrm{NDC}}\left(\mathrm{CO}_{2} \mathrm{Ce}_{d, t, s}\right)\right]\right. \\
& \left.\cdot \prod_{\mathrm{nt}=2}^{t} \operatorname{prob}_{\mathrm{nt}, s}\right\},
\end{aligned}
$$

where $\mathrm{CO}_{2}$ pipe $\mathrm{P}_{i, t, s}$ is carbon emissions of pipe $i$ installed in period $t$ and in scenario $s$ and $\mathrm{CO}_{2} \mathrm{Ce}_{d, t, s}$ are carbon emissions of energy consumed by pump operation under demand condition $d$ for period $t$ and in scenario $s$.

The carbon costs are given by summing the emissions related to pipeline construction with the carbon emissions by pump operation. These emissions are computed for the first time period or phase by the first two terms in (8) and by a weighted sum of the carbon emissions of all the possible future scenarios that can be taken. The future carbon emissions are also computed by summing the pipeline construction with the pump operation carbon emissions.

3.3. Constraints. The multiobjective model also includes a set of constraints. The minimum admissible pressures are used to compute the lowest value of pressure that can be reached according to the probabilities of scenarios and calculated by the following expression:

$$
P_{n, d, t, s} \geq\left[\left(\operatorname{Pdm}_{n, d}-\operatorname{Pam}_{n, d}\right) \cdot \prod_{n t=2}^{t} \operatorname{prob}_{n t, s}\right]+\operatorname{Pam}_{n, d}
$$

$\forall n \in \mathrm{NN} ; \forall d \in \mathrm{NDC} ; \forall t \in \mathrm{NTI} ; \forall s \in \mathrm{NS}$,

where $\operatorname{Pam}_{n, d}$ is minimum admissible pressure at node $n$ for demand condition $d$.

The constraint of (9) is intended to obtain higher minimum pressures, and thus fewer pressure violations, for scenarios with high probabilities of occurrence. This can be seen as a procedure to increase the performance of the network to handle certain, more probable, situations. The model also includes other constraints to verify nodal continuity (see (10)), to compute the head loss of the pipes (see (11)), and to guarantee a minimum pipe diameter (see (12)) for each pipe, the use of a set of commercial diameters (see (13)) and the assignment of only one commercial diameter for each pipe (see (14)).

$$
\begin{aligned}
\sum_{i=1}^{\mathrm{NPI}} I_{n, i} Q_{i, d, t, s} & =\mathrm{QC}_{n, d, t, s} \\
\forall n & \in \mathrm{NN} ; \forall d \in \mathrm{NDC} ; \forall t \in \mathrm{NTI} ; \forall s \in \mathrm{NS} \\
\Delta H_{i, d, t, s} & =K_{i} Q_{i, d, t, s}^{\alpha} \\
\forall n & \in \mathrm{NN} ; \forall d \in \mathrm{NDC} ; \forall t \in \mathrm{NTI} ; \forall s \in \mathrm{NS} \\
D_{i} & \geq \operatorname{Dmin}_{i} \quad \forall i \in \mathrm{NPI}
\end{aligned}
$$




$$
\begin{aligned}
D_{i} & =\sum_{d=1}^{\mathrm{ND}} Y D_{d, i} \cdot D \operatorname{com}_{d, i} \quad \forall i \in \mathrm{NPI} \\
\sum_{d=1}^{\mathrm{ND}} Y D_{d, i} & =1 \quad \forall i \in \mathrm{NPI}
\end{aligned}
$$

where $I_{n, i}$ is incidence matrix of the network; $Q_{i, d, t, s}$ is flow in pipe $i$ under demand condition $d$ for period $t$ and scenario $s\left(\mathrm{~m}^{3} / \mathrm{s}\right) ; \mathrm{QC}_{n, d, t, s}$ is consumption at node $n$ under demand condition $d$ for period $t$ and scenario $s\left(\mathrm{~m}^{3} / \mathrm{s}\right)$; $\mathrm{NN}$ is number of nodes; $\Delta H_{i, d, t, s}$ is head loss in pipe $i$ under demand condition $d$ for period $t$ and scenario $s ; K_{i}, \alpha$ are coefficients that depend on the physical characteristics of pipe $i ; D_{i}$ is diameter of pipe $i$; Dmin ${ }_{i}$ is minimum diameter of pipe $i$; $Y D_{d, i}$ is binary variable to represent the use of diameter $d$ in pipe $i ; \operatorname{com}_{d, i}$ is commercial diameter $d$ assigned to pipe $i$; and ND is number of commercial diameters.

The optimization model was linked to EPANETpdd [24] pressure-driven hydraulic simulator to verify the hydraulic constraints. This is an extension of the EPANET [25] demand-driven simulator. Water distribution simulation models are usually divided into two groups, the demanddriven and the pressure-driven models. Demand-driven is the traditional analysis and assumes that nodal demands are known and are supplied independently of the pressure values. The pressure-driven analysis is based on a more recent modelling strategy that considers demand not fixed but depending on the pressures in the network [26, 27]. Pressure-driven analysis allows a more realistic prediction of the hydraulic system behaviour of WDN [27, 28]. From a computational point of view, demand-driven analysis is more efficient than pressure-driven due to the increased complexity of the hydraulic modelling problem as set out by Giustolisi and Walski [28]. However, pressure-driven analysis is required here to predict the hydraulic behaviour of the network in pressure-deficient conditions. EPANETpdd is used to calculate the hydraulic equations by an iterative procedure presented by Morley and Tricarico [24]. This procedure follows the head-flow relationship proposed by Wagner et al. [29].

\section{Case Study}

We use a WDN adapted from Walski et al. [30] to demonstrate the applicability of our approach, and this is presented in Figure 2. It is a small network supplied by three reservoirs with fixed levels and a pumping station at link 1 to transfer energy to the flow from reservoir 1 .

The grey areas (A1 to A5) of the network in Figure 2 are explained at the end of this section. The grey shades are used to identify the network areas that will be expanded at different phases of the planning horizon or with a population shrinkage. Light grey represents the network areas to be installed in near future (A1, A2) and dark grey represents the areas that will be installed over the long term $(\mathrm{A} 3, \mathrm{~A} 4)$ and A5 where a population shrinkage is considered.

The characteristics of the nodes including the areas, the ground elevation, the demand for conditions (1) and (2), and

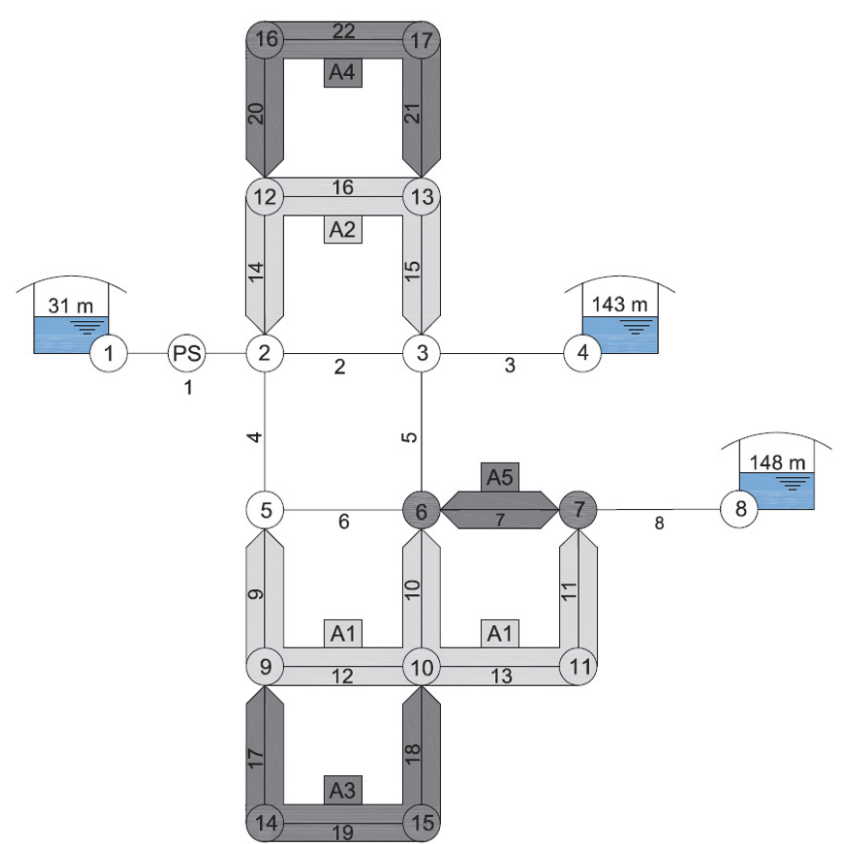

FIgURE 2: Water distribution network.

two different minimum pressures for each demand condition are given in Table 1 . We consider two different minimum pressure values to design the network for the long term, the desired pressure (minimum pressure to provide a good level of network service) and admissible pressure (minimum allowed pressures in the network below which no demand can be delivered). Pressure at the nodes can be lower than the desired pressure but not lower than the admissible pressure.

The characteristics of the pipes are given in Table 2, namely, the initial and final nodes, the length, and the pipes to be installed according to the areas of Figure 2 .

In relation to the pump (pipe ID 1), the efficiency is $75 \%$ and the daily consumption is 20 hours at demand condition (1) and the other 4 hours at demand condition (2). The energy costs are $0.075 \mathrm{USD} / \mathrm{kWh}$ and should be evaluated for a 60 year period at a discount rate of $4 \%$ per year. This rate was fixed based on recommendations by Wu et al. [31].

Eight possible commercial diameters are considered for the optimal design of the WDN and these are presented in Table 3, including (for each commercial diameter) the unit cost, the Hazen-Williams coefficients, and the carbon emissions. These carbon emissions are computed by the procedure described by Marques et al. [23] .

The planning horizon for this case study is set at 60 years and divided into three periods or phases of 20 years each, when different options can be taken. These options are stated according to the uncertainty of future outcomes and are organized by ROs in terms of possible future scenarios. The dynamics of urban growth over the lifetime horizon have a considerable impact on the WDN and should therefore be taken into account at the infrastructure planning stage. 
TABLE 1: Characteristics of the nodes.

\begin{tabular}{|c|c|c|c|c|c|c|c|c|}
\hline \multirow[t]{2}{*}{ Node } & \multirow[t]{2}{*}{ Area } & \multirow[t]{2}{*}{ Ground elevation (m) } & \multicolumn{2}{|c|}{$\begin{array}{l}\text { Nodal demand } \\
\text { condition }(1 / \mathrm{s})\end{array}$} & \multicolumn{2}{|c|}{$\begin{array}{l}\text { Minimum desirable } \\
\text { pressure }(\mathrm{m})\end{array}$} & \multicolumn{2}{|c|}{$\begin{array}{c}\text { Minimum admissible } \\
\text { pressure }(\mathrm{m})\end{array}$} \\
\hline & & & $(1)$ & $(2)$ & $(1)$ & $(2)$ & (1) & $(2)$ \\
\hline 1 & & 36.5 & \multicolumn{6}{|c|}{ Reservoir at the level of $30.5 \mathrm{~m}$} \\
\hline 2 & & 30.5 & 0 & 0 & 28.1 & 17.6 & 21.1 & 10.6 \\
\hline 3 & & 106.7 & 31.6 & 47.3 & 28.1 & 17.6 & 21.1 & 10.6 \\
\hline 4 & & 117.4 & \multicolumn{6}{|c|}{ Reservoir at the level of $143.3 \mathrm{~m}$} \\
\hline 5 & & 106.7 & 31.6 & 47.3 & 28.1 & 17.6 & 21.1 & 10.6 \\
\hline 6 & A5 & 106.7 & 126.2 & 189.3 & 28.1 & 17.6 & 21.1 & 10.6 \\
\hline 7 & A5 & 106.7 & 63.1 & 94.6 & 28.1 & 17.6 & 21.1 & 10.6 \\
\hline 8 & & 121.9 & \multicolumn{6}{|c|}{ Reservoir at the level of $147.8 \mathrm{~m}$} \\
\hline 9 & $\mathrm{~A} 1$ & 106.7 & 31.6 & 47.3 & 28.1 & 17.6 & 21.1 & 10.6 \\
\hline 10 & $\mathrm{~A} 1$ & 106.7 & 31.6 & 47.3 & 28.1 & 17.6 & 21.1 & 10.6 \\
\hline 11 & $\mathrm{~A} 1$ & 106.7 & 31.6 & 47.3 & 28.1 & 17.6 & 21.1 & 10.6 \\
\hline 12 & $\mathrm{~A} 2$ & 106.7 & 31.6 & 47.3 & 28.1 & 17.6 & 21.1 & 10.6 \\
\hline 13 & $\mathrm{~A} 2$ & 106.7 & 31.6 & 47.3 & 28.1 & 17.6 & 21.1 & 10.6 \\
\hline 14 & A3 & 106.7 & 31.6 & 47.3 & 28.1 & 17.6 & 21.1 & 10.6 \\
\hline 15 & $\mathrm{~A} 3$ & 106.7 & 31.6 & 47.3 & 28.1 & 17.6 & 21.1 & 10.6 \\
\hline 16 & $\mathrm{~A} 4$ & 106.7 & 31.6 & 47.3 & 28.1 & 17.6 & 21.1 & 10.6 \\
\hline 17 & A4 & 106.7 & 31.6 & 47.3 & 28.1 & 17.6 & 21.1 & 10.6 \\
\hline
\end{tabular}

TABLE 2: Characteristics of the pipes.

\begin{tabular}{|c|c|c|c|c|}
\hline Pipe ID & Initial node & Final node & Length (m) & Area \\
\hline 1 & 1 & 2 & Pump & \\
\hline 2 & 2 & 3 & 3218.7 & \\
\hline 3 & 3 & 4 & 3218.7 & \\
\hline 4 & 2 & 5 & 1609.3 & \\
\hline 5 & 3 & 6 & 1609.3 & \\
\hline 6 & 5 & 6 & 3218.7 & \\
\hline 7 & 6 & 7 & 3218.7 & A5 \\
\hline 8 & 7 & 8 & 1609.3 & \\
\hline 9 & 5 & 9 & 1609.3 & $\mathrm{~A} 1$ \\
\hline 10 & 6 & 10 & 1609.3 & $\mathrm{~A} 1$ \\
\hline 11 & 7 & 11 & 1609.3 & $\mathrm{~A} 1$ \\
\hline 12 & 9 & 10 & 3218.7 & A1 \\
\hline 13 & 10 & 11 & 3218.7 & A1 \\
\hline 14 & 2 & 12 & 1609.3 & $\mathrm{~A} 2$ \\
\hline 15 & 3 & 13 & 1609.3 & $\mathrm{~A} 2$ \\
\hline 16 & 12 & 13 & 3218.7 & $\mathrm{~A} 2$ \\
\hline 17 & 9 & 14 & 1609.3 & A3 \\
\hline 18 & 10 & 15 & 1609.3 & A3 \\
\hline 19 & 14 & 15 & 3218.7 & A3 \\
\hline 20 & 12 & 16 & 1609.3 & A4 \\
\hline 21 & 13 & 17 & 1609.3 & A4 \\
\hline 22 & 16 & 17 & 3218.7 & A4 \\
\hline
\end{tabular}

A decision tree is built for the case study using the various decision paths that can be taken in future and it is presented in Figure 3.
TABle 3: Diameter, unit costs, carbon emissions, and HazenWilliams coefficients.

\begin{tabular}{lccc}
\hline $\begin{array}{l}\text { Diameters } \\
(\mathrm{mm})\end{array}$ & $\begin{array}{c}\text { Unit costs } \\
(\mathrm{USD} / \mathrm{m})\end{array}$ & $\begin{array}{c}\text { Hazen- } \\
\text { Williams } \\
\text { coefficients }\end{array}$ & $\begin{array}{c}\text { Carbon } \\
\text { emissions } \\
\left.\text { (ton } \mathrm{CO}_{2} / \mathrm{m}\right)\end{array}$ \\
\hline 152.4 & 49.5 & 100 & 0.5 \\
203.2 & 63.3 & 100 & 0.6 \\
254 & 94.8 & 100 & 0.7 \\
304.8 & 132.9 & 100 & 0.8 \\
355.6 & 170.9 & 100 & 0.9 \\
406.4 & 194.9 & 100 & 1.0 \\
457.2 & 225.1 & 100 & 1.1 \\
508 & 262.8 & 100 & 1.1 \\
\hline
\end{tabular}

The planning horizon, represented in the decision tree, is divided into three time periods. In the first time period, $t=1$, the network design is required for pipes 1 to 8 , allowing for future uncertainty. In $t=2$ (light grey), there are four options available, expansion to $\mathrm{A} 1$ and $\mathrm{A} 2$, expansion to $\mathrm{Al}$, expansion to A2 and do not expand. For the last time period (dark grey), $t=3$, other options are possible, that is, expansion to A3 and A4, expansion to A3, expansion to A4, and do not expand. A population shrinkage is also considered, A5, that sees consumption fall by $30 \%$. These future conditions are considered the most probable and are organized in the decision tree by phased interventions in the network that can be made by following a decision path in the decision tree. Each decision option has a probability shown in the squares in Figure 3 and the probabilities of scenarios given in the last 


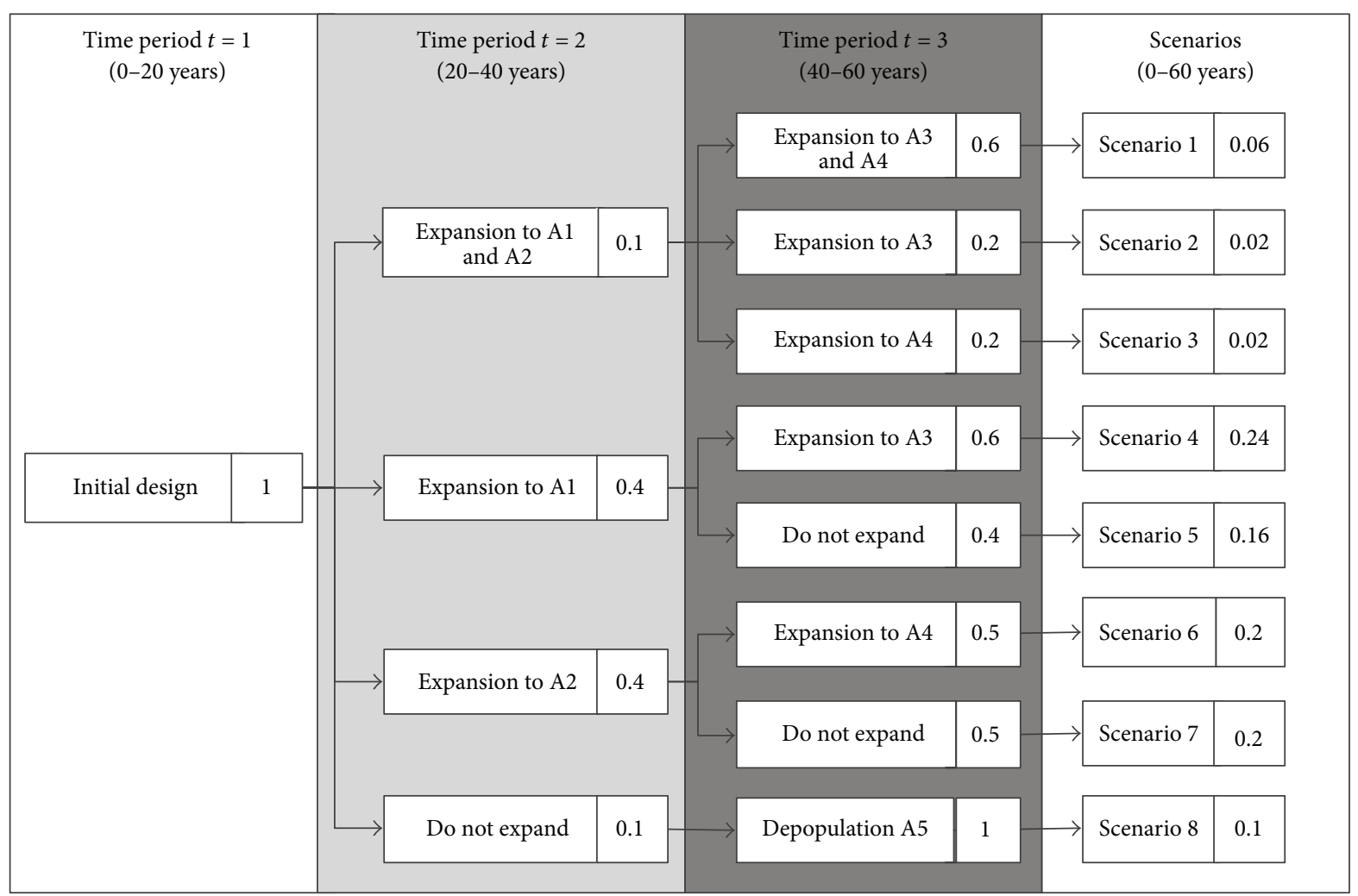

FIGURE 3: Decision tree for the planning horizon and occurrence probability.

branches of the decision tree are computed with these values by multiplying all the probability values on the decision path of the scenario. In real world applications these probabilities can be given by expert judgement.

\section{Results}

Keeping the problem formulation and the case study in mind, the results are identified for all the design phases and for all scenarios of the planning horizon. However, as previously stated, just the first phase of the design has to be built now and the process can be reassessed in subsequent phases to find more accurate solutions once some uncertainty has been eliminated. The solutions were obtained by using the multiobjective simulated annealing algorithm and the results are plotted in Figure 4.

A global view of the three objectives' possible Pareto front is shown in Figure 4 by a set of 600 solutions. This representation makes use of the AEROVIS visualization tool developed by Kollat and Reed [32] and Kollat et al. [22]. These solutions are plotted for different perspectives to try to facilitate the visualization of the shape of the Pareto front surface so as to indicate the type of trade-off between the different objectives.

The colour scheme of the figures shows the cost of the solutions in US dollars. The colder (blue) shades represent the lower values of cost and the warmer (red) shades represent the higher values. The colour scheme and the relevant cost values are indicated in the colour bars above the figures.
The trade-offs between the multiobjective optimization solutions are explored in detail by plotting these results in two-dimensional graphs by pair of objectives. This is done using the AEROVIS visualization tool to emphasize the nondominated solutions between each pair of objectives and soften the others. Figure 5 shows the costs plotted with pressure deficits.

This figure shows that increasing the cost leads to decreasing the hydraulic pressure deficits. For total pressures deficits below approximately $60(\mathrm{~m})$, the rate of cost increase is much higher than for pressure deficits above $60(\mathrm{~m})$. In relation to cost and carbon emissions, the trade-offs between these two objectives are presented in Figure 6.

It can be seen from the figure that the carbon emissions are not in conflict with the cost objective. Roughly, decreasing the amount of material for pipes and the energy consumed by pumps makes it possible to reduce both the cost and the carbon emissions. Finally, Figure 7 shows the relation between the carbon emissions and the pressure deficits.

It can be seen from this figure that the hydraulic pressure deficit is reduced by increasing the carbon emissions. In fact, the reduction of the pressure deficits is achieved by increasing the network's hydraulic capacity. This can be done by introducing large-diameter pipe sections or by increasing the energy used for pumping. Both imply more carbon emissions through the rise in the quantity of pipe material needed and in the energy consumed by pumps.

To understand the importance of including a carbon emissions objective in the optimization model, the results 

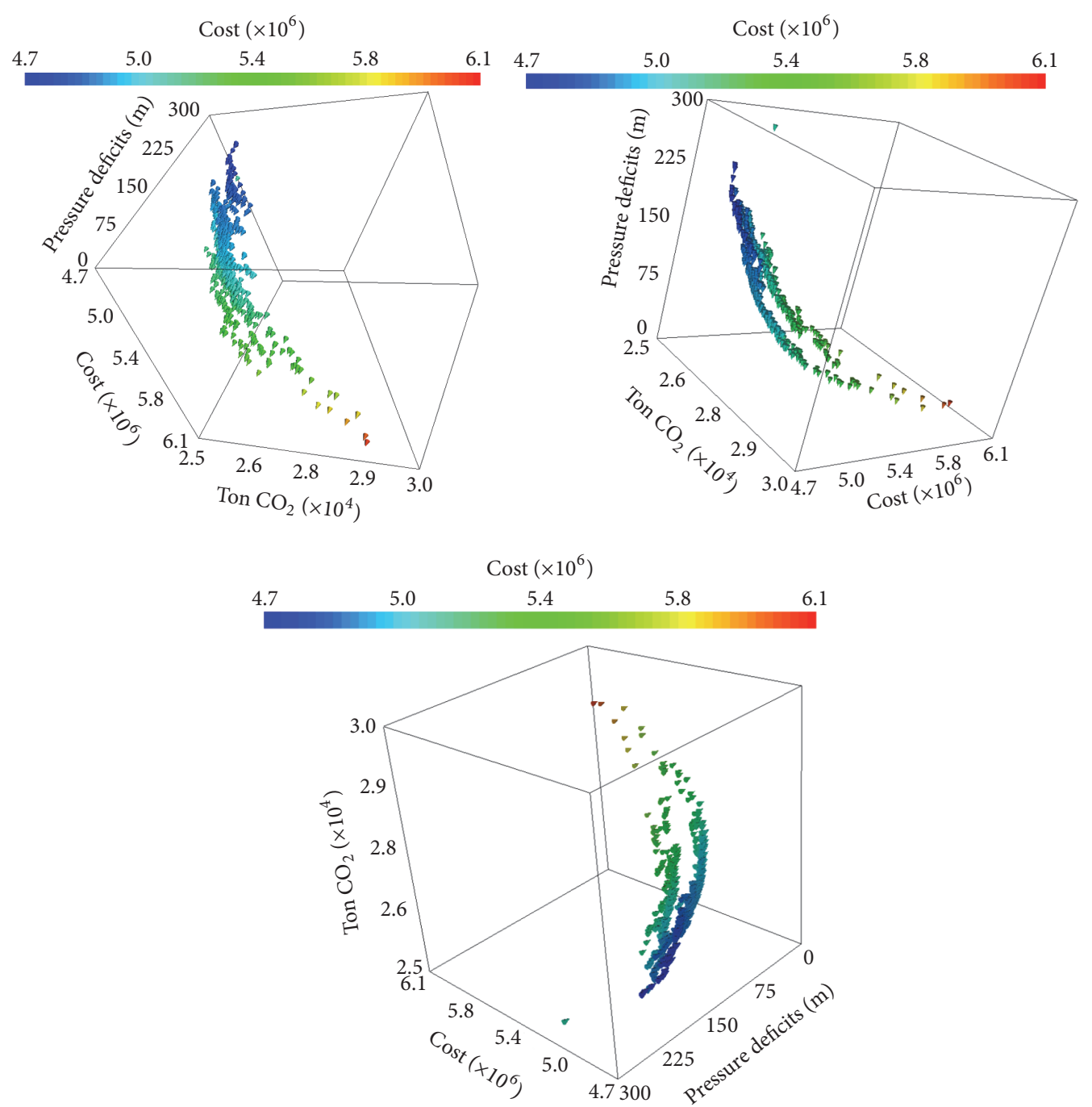

FIgURE 4: Pareto front from different perspectives.

of the optimization model described previously, abbreviated as OMl, are compared with the results of the optimization model OM2 that do not include carbon emissions as an objective to minimize. OM1 (described in Section 3) has three objective functions included in expressions (1), (2), and (3), to minimize costs, pressure deficits, and carbon emissions, respectively. The OM2 model has the two objective functions presented in expressions (15). These expressions are equal to expressions (1) and (2) of OM1.

$$
\begin{aligned}
& \mathrm{O} 1=\min (\mathrm{Ci}+\mathrm{Cf}) \\
& \mathrm{O} 2=\min (\mathrm{HPD}) .
\end{aligned}
$$

The OM2 constraints are included in (9) to (14) (the same as for OM1). The results of OM2 are compared with the OM1 solutions in Figures 8 and 9. As before, the AEROVIS visualization tool is used to show the results. In OM2 the carbon emissions are not minimized, although to allow the comparison, carbon emissions are computed after the optimization run to enable these solutions to be shown in the same layout scheme. Figure 8 compares the OM1 solutions (Figure 8(a)) with the OM2 solutions (Figure 8(b)) in terms of cost and carbon emissions. Two solutions are marked inside a black box. The cost of these solutions is practically the same $\left(4.89 \times 10^{6}\right.$ USD versus $4.86 \times 10^{6}$ USD), but the OM1 solution has 722 tonnes less $\mathrm{CO}_{2}$ emissions than the OM2 solution. Figure 9 shows the comparisons of solutions, in terms of carbon emissions and pressure deficits, identified by OM1 (Figure 9(a)) with the OM2 (Figure 9(b)). Two solutions are also marked inside a red box. This means they have almost the same value of pressure deficits ( $146 \mathrm{~m}$ versus $145 \mathrm{~m}$ ), but the OM1 solution has 948 tonnes less $\mathrm{CO}_{2}$ emissions than the OM2 solution.

These results show the advantage of using a threeobjective optimization model (OM1) to design WDNs. The ROs approach used here includes a multiphased design of the WDN that has to define the initial design (for the first phase) and helps decision makers to investigate different future options during the planning horizon. The results for the case study that are presented in Figure 4 show the values 


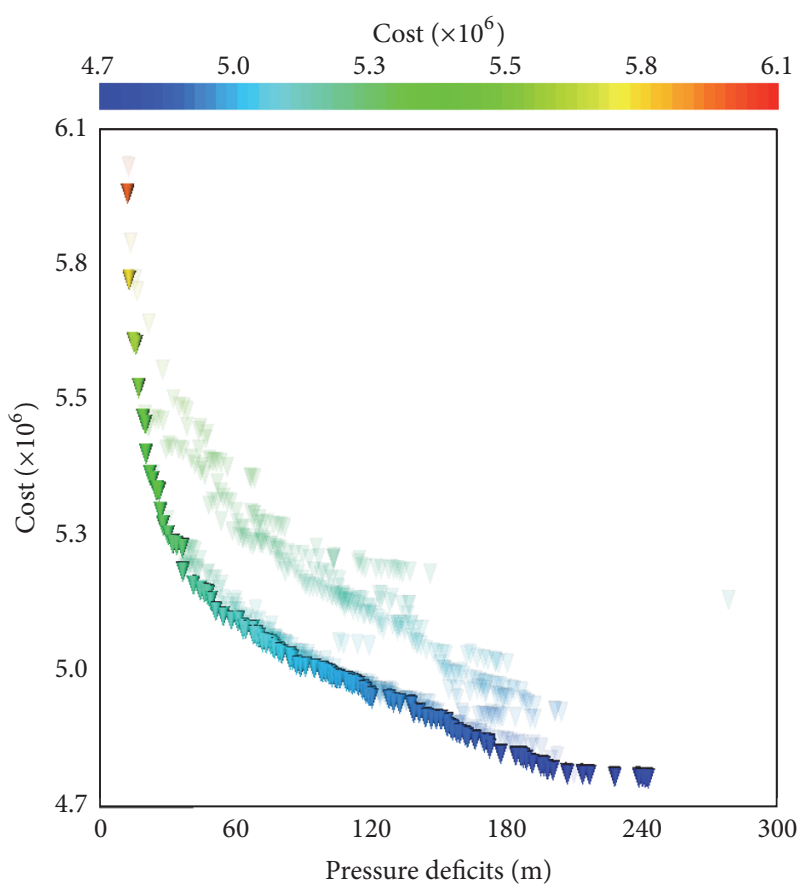

Figure 5: Pareto front of cost versus pressure deficit.

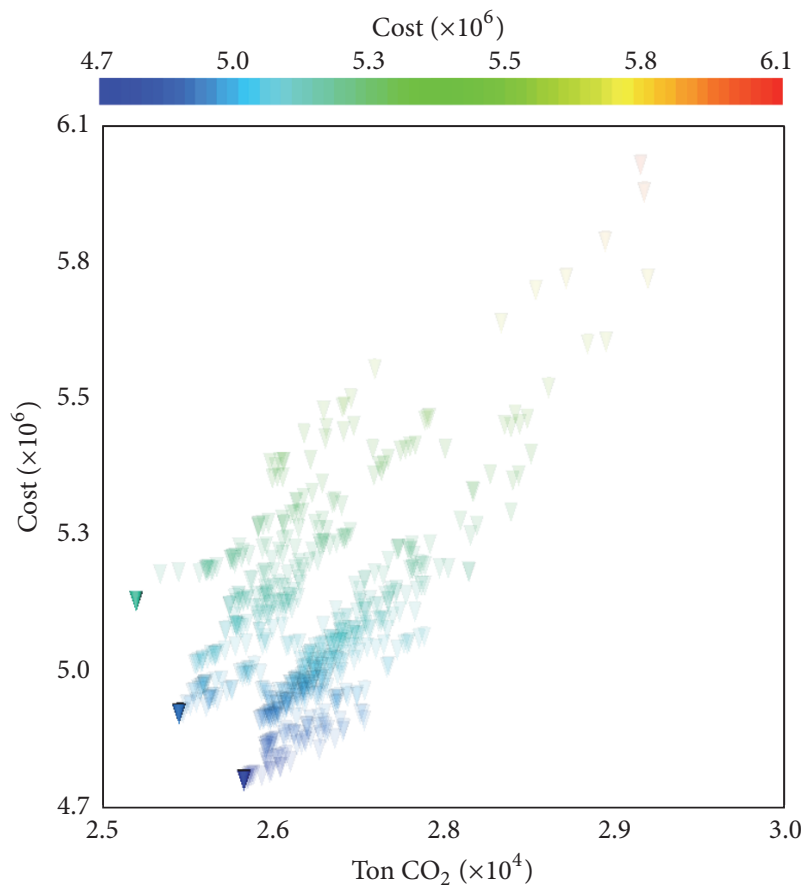

FIgURE 6: Pareto front of cost versus ton $\mathrm{CO}_{2}$.

for the three objective functions for each solution. Each of these solutions can be detailed according to the effective WDN design for the different possible future options.

The effective design of three different WDN solutions of the Pareto front is presented in Figure 10, taking the decision path of scenario 1 into account, in which all the expansion areas are developed. Although only this scenario is

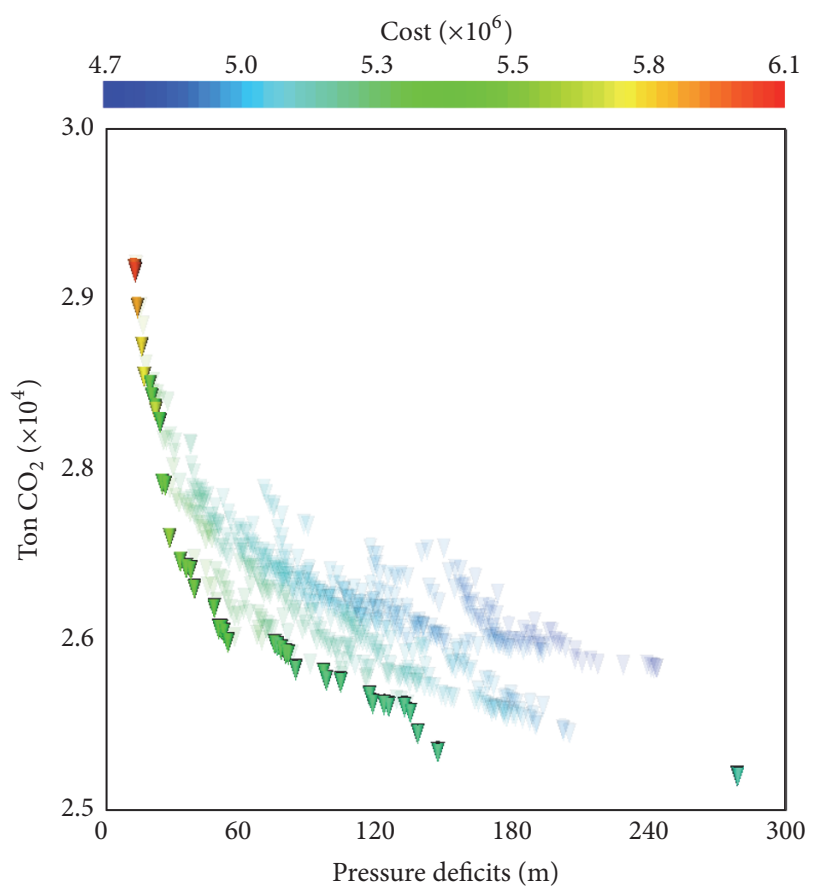

Figure 7: Pareto front of ton $\mathrm{CO}_{2}$ versus pressure deficits.

represented, the approach presented does identify the designs for all the other scenarios. Furthermore, these designs are presented according to the three phased interventions in the network. The first design phase $(t=1)$ is in fact the solution that has to start being implemented now, taking the future expansion options into account. In this phase, pipes 2 to 8 are designed with enough hydraulic capacity to cope with all possible future scenarios. Nonetheless, the case study includes a pumping station downstream of reservoir R1 (see Figure 2) that can be used to increase the network node pressures, if required. There is therefore a compromise between increasing the hydraulic capacity of pipes with an initially high construction investment or increasing the head of the pumps and spending more on energy.

Figure 10 is divided into three to show the solutions for the phased designs, using light grey for the network areas to be installed in phase $(t=2)$ and dark grey for the areas that will be installed in phase $(t=3)$. Figure 10(a) shows the lowest cost design solution. Figure 10(b) shows a solution with the lowest hydraulic pressure deficit, and Figure 10(c) represents a solution with the lowest carbon emissions.

It is possible to draw some conclusions from Figure 10. In terms of pipe diameters, the solution with the lowest cost uses the smallest pipe diameters (Figure 10(a)). Conversely, the solution with large pipe diameters is also the most expensive solution and has the lowest pressure deficit (Figure 10(b)). To reduce the pressure deficit, the pipe diameters need to increase, which in turn will increase the cost and also the carbon emissions. Finally, low carbon emissions can be obtained with a low cost solution, but with high hydraulic pressure deficits (Figure 10(c)). It should be emphasized that Figure 10 shows only the design of the WDN for one of the 


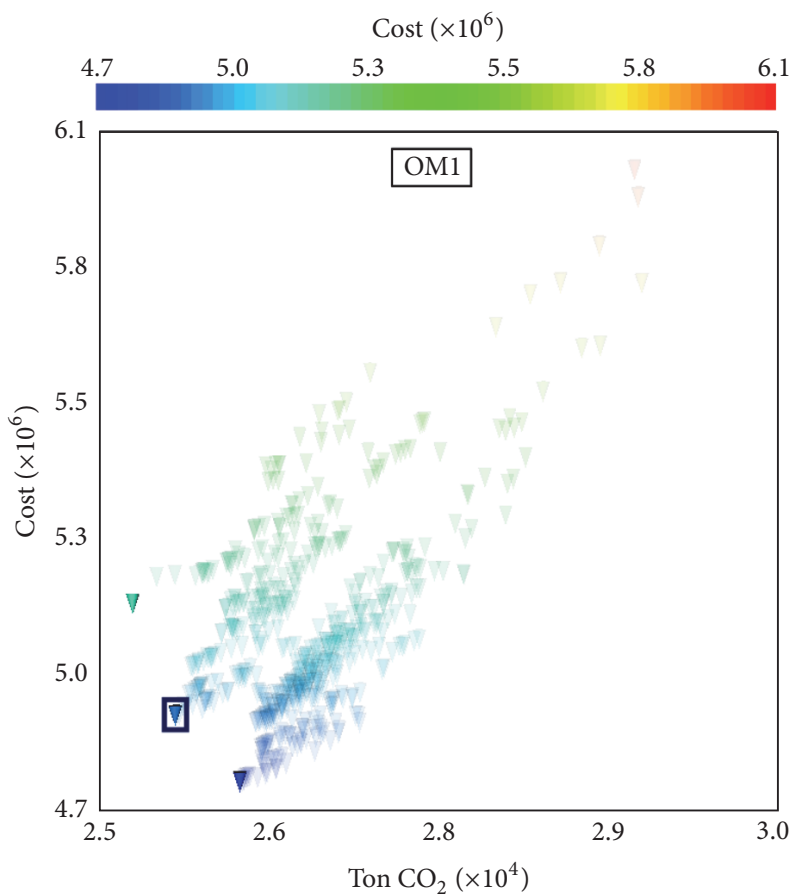

(a)

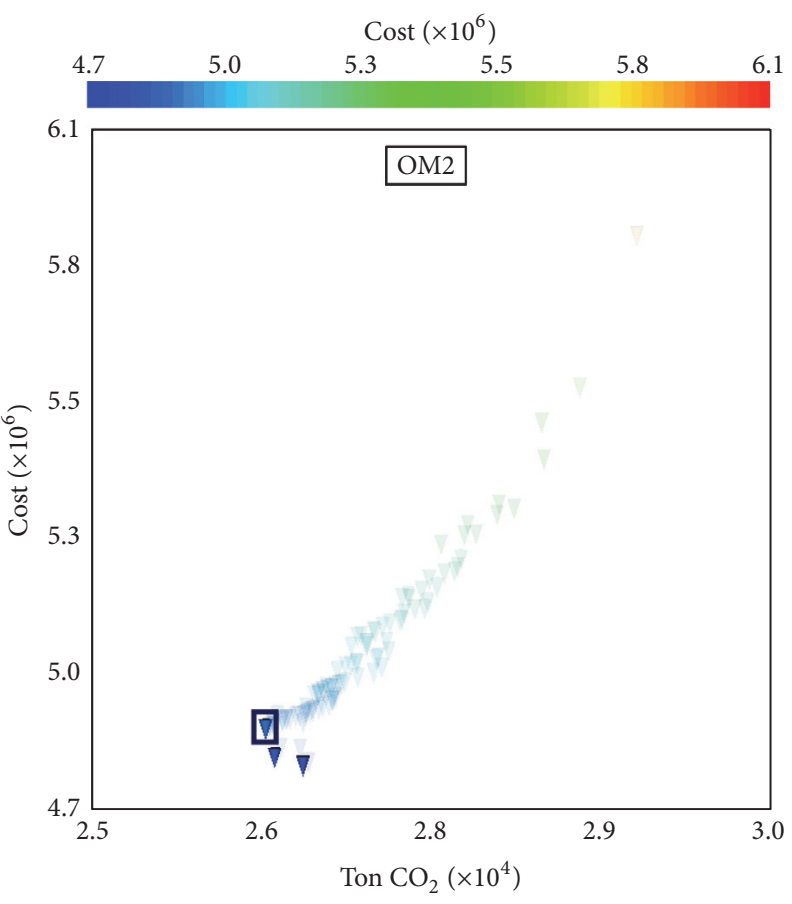

(b)

Figure 8: (a) Cost versus ton $\mathrm{CO}_{2}$ for OM1; (b) cost versus ton $\mathrm{CO}_{2}$ for OM2.

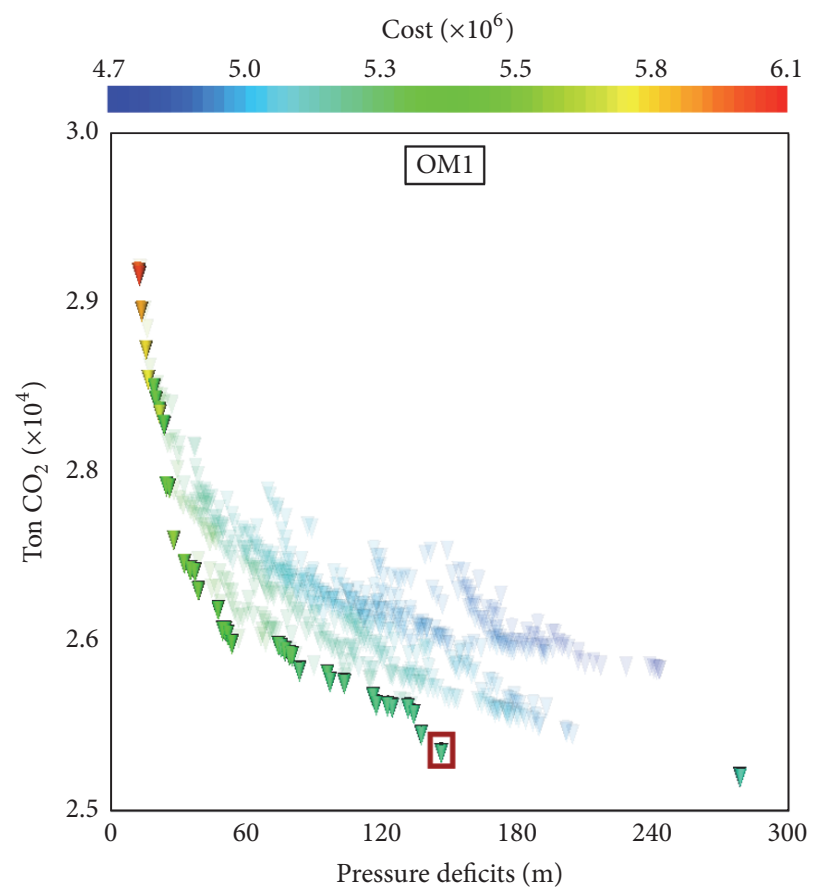

(a)

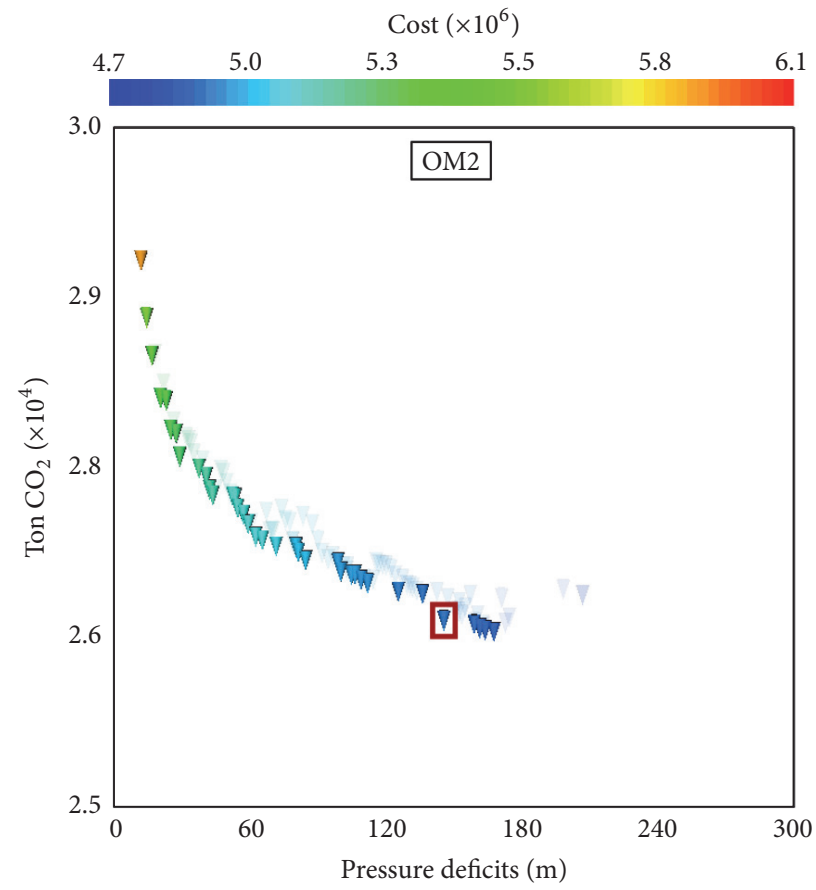

(b)

Figure 9: (a) Ton $\mathrm{CO}_{2}$ versus pressure deficits for OM1; (b) ton $\mathrm{CO}_{2}$ versus pressure deficits for OM2. 


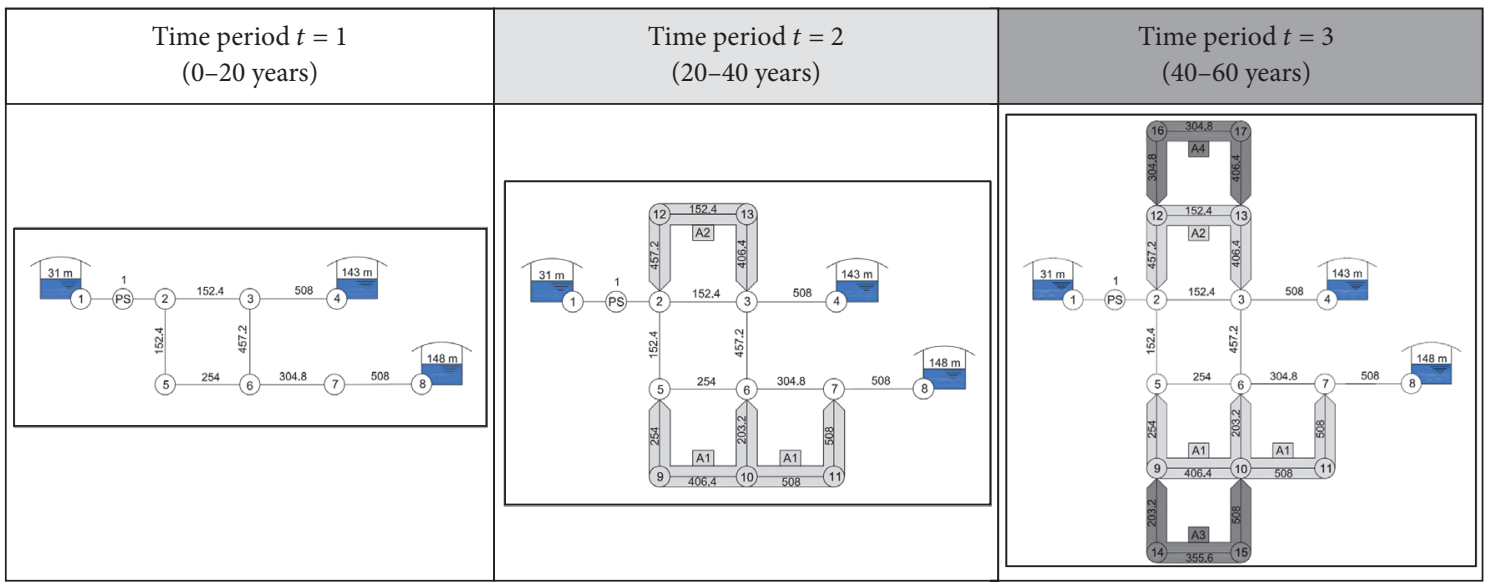

(a)

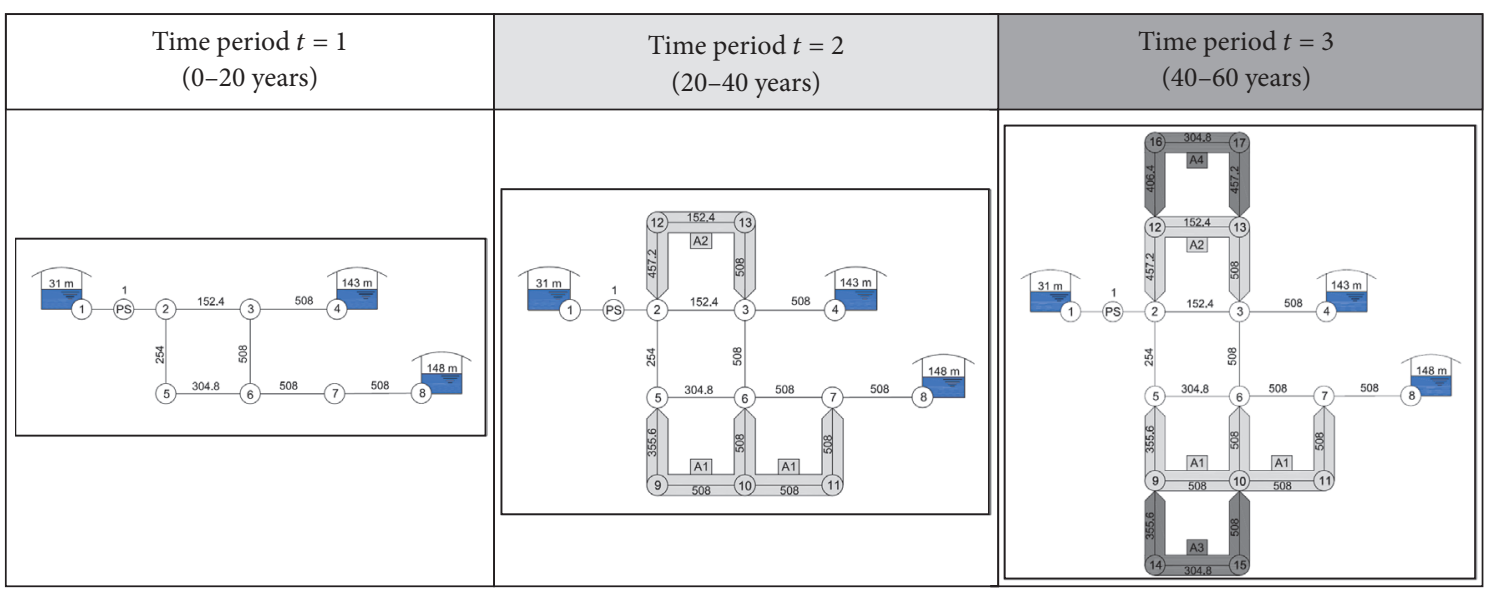

(b)

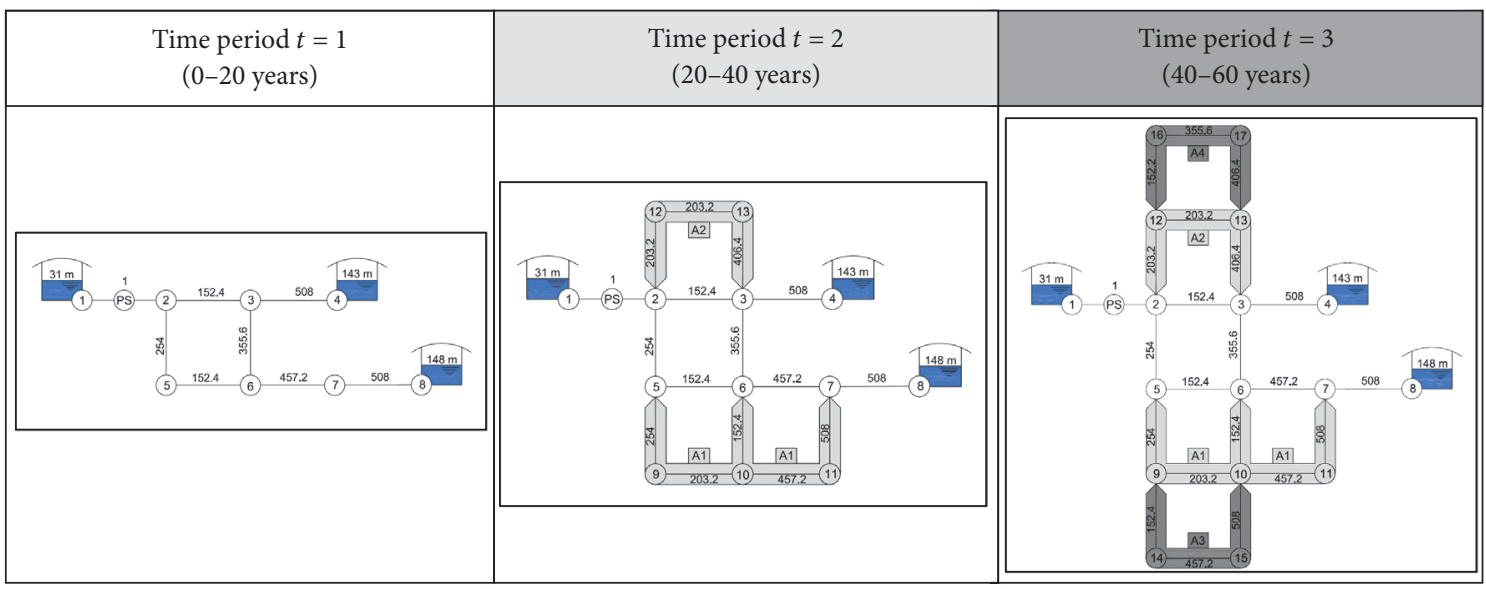

(c)

FIGURE 10: Water distribution network considering scenario 1 and the lowest cost solution (a); the lowest pressure deficit solution (b); and the lowest carbon emissions solution (c).

possible scenarios (scenario 1). However, all the solutions of the Pareto front, which are obtained by the multiobjective model, include the designs for all the other scenarios.

Summing up, the results and the comparisons set out in this work comprise the optimal solutions in terms of the diameter of the pipes to be laid in each of the design phases. The proposed approach has the advantage of offering stakeholders trade-offs between the objectives of cost, pressure deficits and carbon emissions, while at the same time supporting decision making by identifying solutions for the 
first design phase and keeping the temporal development of WDNs in sight. Furthermore, comparison of the results of the OM1 and OM2 models shows that there are advantages in including carbon emissions as a specific objective in OM1, which can find solutions with lower carbon emissions for the same level of costs and same level of pressure deficits as the OM2 solutions.

\section{Conclusions}

This paper describes a ROs multiobjective and multiphase optimization approach for the flexible design and operation of WDNs under uncertainty. The proposed optimization model minimizes the costs, the extent of hydraulic pressure deficits and the total carbon emissions. A case study has been used to validate the approach and the results are presented in a Pareto front by using an appropriate visualization tool. The Pareto front surfaces obtained show the trade-off between the three objectives. The geometry of Pareto fronts enables some interesting conclusions to be drawn in terms of the possible compromise between the objectives and how a decrease achieved in one objective influences the increase in the others. For example, to achieve a low pressure deficit solution, the rate of increase in the required investment must grow much faster beyond certain pressure deficit threshold $(60 \mathrm{~m})$. On the other hand, carbon emissions do not appear to be in conflict with the cost objective as reducing the pipe material quantities and the energy consumed by pumps lowers both the cost and the carbon emissions. Finally, the results show that pressure deficit reduction can only be achieved by increasing carbon emissions.

The results of this paper also stem from comparisons between two models to ascertain the importance of including carbon emissions minimization as an objective in the optimization model. The results show that it is possible to reduce the $\mathrm{CO}_{2}$ emitted for the same level of capital expenditure or the same level of network pressure deficits if carbon emissions are minimized in the optimization process. Finally, three particular solutions for the network design, retrieved from the edges of the Pareto front, are detailed to compare the pipe size changes when preference is given to one of the objectives. The results indicate the increase in pipe sizes observed for a solution with the lowest demand deficits relative to solutions obtained for the lowest cost and with the lowest carbon emissions. From a decision-making point of view, results of this kind can help decision makers to better understand the impact of assigning more importance to one objective relative to another.

The consideration of ROs permits uncertainty to be included in the decision process by using phased planning that makes it possible to undertake midcourse adjustments or make additional investments. It should be emphasized that the multiphase design of WDNs enables decision makers to postpone interventions in the network until such time as they are required, thus reducing the construction costs at year zero compared with the traditional single-phase design. The methodology proposed in this paper supports decisions taken for the first phase that can be adjusted if required, and as new information becomes available. The adjustments are predefined in a decision tree where different scenarios with specific occurrence probability are stated. However, given the large uncertainty in such long planning horizon, the process can be reassessed at the end of each phase in response to inaccuracies in the scenario or demand forecasts. The use of ROs gives a measure of flexibility to decision making.

\section{Competing Interests}

The authors declare that they have no competing interests.

\section{Acknowledgments}

This study had the support of Fundação para a Ciência e Tecnologia (FCT), through the Strategic Project UID/MAR/ 04292/2013 granted to MARE.

\section{References}

[1] S. C. Myers, "Determinants of corporate borrowing," Journal of Financial Economics, vol. 5, no. 2, pp. 147-175, 1977.

[2] D. Wörsdörfer, S. Lier, and N. Crasselt, "Real options-based evaluation model for transformable plant designs in the process industry," Journal of Manufacturing Systems, vol. 42, pp. 29-43, 2017.

[3] J. A. Schachter and P. Mancarella, "A critical review of Real Options thinking for valuing investment flexibility in Smart Grids and low carbon energy systems," Renewable and Sustainable Energy Reviews, vol. 56, pp. 261-271, 2016.

[4] J. Savolainen, "Real options in metal mining project valuation: review of literature," Resources Policy, vol. 50, pp. 49-65, 2016.

[5] J. Buurman and V. Babovic, "Adaptation Pathways and Real Options Analysis: an approach to deep uncertainty in climate change adaptation policies," Policy and Society, vol. 35, no. 2, pp. 137-150, 2016.

[6] M. Woodward, Z. Kapelan, and B. Gouldby, "Adaptive flood risk management under climate change uncertainty using real options and optimization," Risk Analysis, vol. 34, no. 1, pp. 7592, 2014.

[7] D. Huang, K. Vairavamoorthy, and S. Tsegaye, "Flexible design of urban water distribution networks," in Proceedings of the World Environmental and Water Resources Congress, pp. 42254236, Providence, RI, USA, May 2010.

[8] I. Basupi and Z. Kapelan, "Flexible water distribution system design under future demand uncertainty," Journal of Water Resources Planning and Management, vol. 141, no. 4, Article ID 04014067, 2015.

[9] I. Basupi and Z. Kapelan, "Evaluating flexibility in water distribution system design under future demand uncertainty," Journal of Infrastructure Systems, vol. 21, no. 2, Article ID 4014034, 2015.

[10] J. Marques, M. Cunha, and D. A. Savić, "Multi-objective optimization of water distribution systems based on a real options approach," Environmental Modelling and Software, vol. 63, pp. 1-13, 2015.

[11] E. Alperovits and U. Shamir, "Design of optimal water distribution systems," Water Resources Research, vol. 13, no. 6, pp. 885900, 1977.

[12] D. Savic, "Single-objective vs. Multiobjective optimisation for integrated decision support," in Proceedings of the 1st Biennial 
Meeting of the International Environmental Modelling and Software Society, pp. 7-12, 2002.

[13] L. M. Herstein, Y. R. Filion, and K. R. Hall, "Evaluating the environmental impacts of water distribution systems by using EIO-LCA-based multiobjective optimization," Journal of Water Resources Planning and Management, vol. 137, no. 2, pp. 162-172, 2011.

[14] M. D’Ercole, M. Righetti, R. M. Ugarelli, L. Berardi, and P. Bertola, "An integrated modeling approach to optimize the management of a water distribution system: improving the sustainability while dealing with water loss, energy consumption and environmental impacts," Procedia Engineering, vol. 162, pp. 433-440, 2016.

[15] S. Kirkpatrick, J. Gelatt, and M. P. Vecchi, "Optimization by simulated annealing," American Association for the Advancement of Science. Science, vol. 220, no. 4598, pp. 671-680, 1983.

[16] N. Metropolis, A. W. Rosenbluth, M. N. Rosenbluth, A. H. Teller, and E. Teller, "Equation of state calculations by fast computing machines," The Journal of Chemical Physics, vol. 21, no. 6, pp. 1087-1092, 1953.

[17] J. A. Zeferino, A. P. Antunes, and M. C. Cunha, "An efficient simulated annealing algorithm for regional wastewater system planning," Computer-Aided Civil and Infrastructure Engineering, vol. 24, no. 5, pp. 359-370, 2009.

[18] L. M. Nunes, E. Paralta, M. C. Cunha, and L. Ribeiro, "Comparison of variance-reduction and space-filling approaches for the design of environmental monitoring networks," ComputerAided Civil and Infrastructure Engineering, vol. 22, no. 7, pp. 489-498, 2007.

[19] M. D. C. Cunha and J. Sousa, "Hydraulic infrastructures design using simulated annealing," Journal of Infrastructure Systems, vol. 7, no. 1, pp. 32-39, 2001.

[20] J. Reca, J. Martínez, C. Gil, and R. Baños, “Application of several meta-heuristic techniques to the optimization of real looped water distribution networks," Water Resources Management, vol. 22, no. 10, pp. 1367-1379, 2008.

[21] J. Reca, J. Martínez, R. Baños, and C. Gil, "Optimal design of gravity-fed looped water distribution networks considering the resilience index," Journal of Water Resources Planning and Management, vol. 134, no. 3, pp. 234-238, 2008.

[22] J. B. Kollat, P. M. Reed, and R. M. Maxwell, "Many-objective groundwater monitoring network design using bias-aware ensemble Kalman filtering, evolutionary optimization, and visual analytics," Water Resources Research, vol. 47, no. 2, pp. 19447973, 2011.

[23] J. Marques, M. Cunha, and D. A. Savić, "Using real options for an eco-friendly design of water distribution systems," Journal of Hydroinformatics, vol. 17, no. 1, pp. 20-35, 2015.

[24] M. S. Morley and C. Tricarico, "Pressure driven demand extension for EPANET (EPANETpdd)," Tech. Rep., Centre for Water Systems, University of Exeter, Exeter, UK, 2008.

[25] L. A. Rossman, "Epanet 2 users manual," Tech. Rep. EPA/600/R00/057, U.S. Environmental Protection Agency, Washington, DC, USA, 2000.

[26] E. Todini, "A more realistic approach to the 'extended period simulation' of water distribution networks," in Proceedings of the Advances in Water Supply Management Symposium (CCWI'03), pp. 173-184, London, UK, September 2003.

[27] O. Giustolisi, D. Savic, and Z. Kapelan, "Pressure-driven demand and leakage simulation for water distribution networks," Journal of Hydraulic Engineering, vol. 134, no. 5, pp. 626-635, 2008.
[28] O. Giustolisi and T. M. Walski, "Demand components in water distribution network analysis," Journal of Water Resources Planning and Management, vol. 138, no. 4, pp. 356-367, 2012.

[29] J. M. Wagner, U. Shamir, and D. H. Marks, "Water distribution reliability: simulation methods," Journal of Water Resources Planning and Management, vol. 114, no. 3, pp. 276-294, 1988.

[30] T. M. Walski, J. Gessler, and J. W. Sjostrom, "Water distribution systems: simulation and sizing," in Environmental Progress, M. Wentzel, Ed., Lewis Publishers, Chelsea, UK, 1990.

[31] W. Wu, A. R. Simpson, and H. R. Maier, "Accounting for greenhouse gas emissions in multiobjective genetic algorithm optimization of water distribution systems," Journal of Water Resources Planning and Management, vol. 136, no. 2, pp. 146$155,2010$.

[32] J. B. Kollat and P. Reed, "A framework for visually interactive decision-making and design using evolutionary multi-objective optimization (VIDEO)," Environmental Modelling and Software, vol. 22, no. 12, pp. 1691-1704, 2007. 


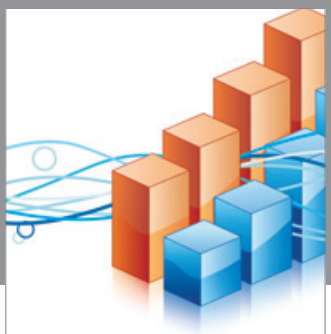

Advances in

Operations Research

vatem alat4

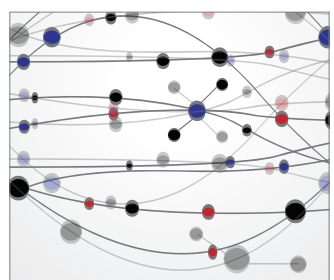

\section{The Scientific} World Journal
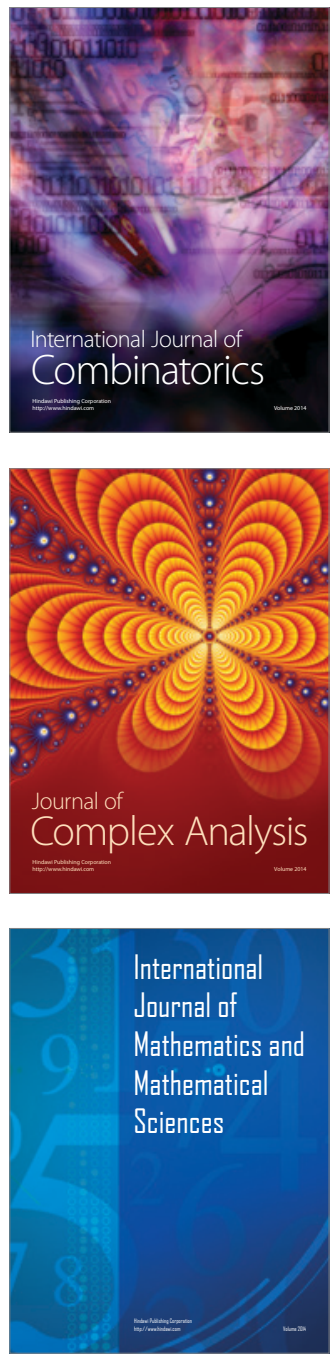
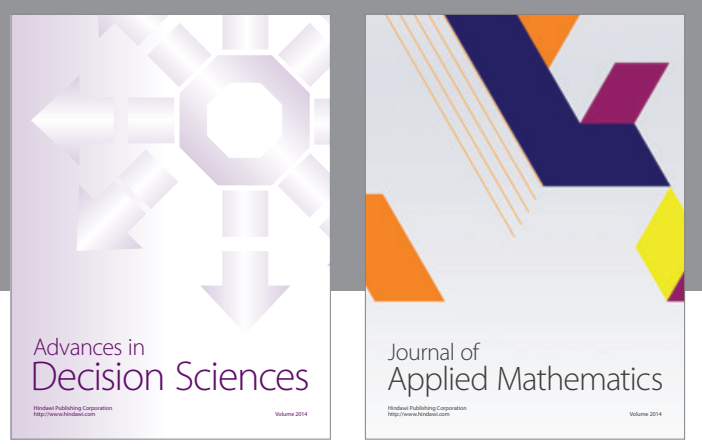

Algebra

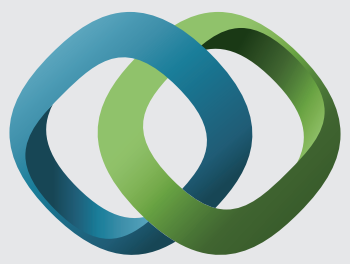

\section{Hindawi}

Submit your manuscripts at

https://www.hindawi.com
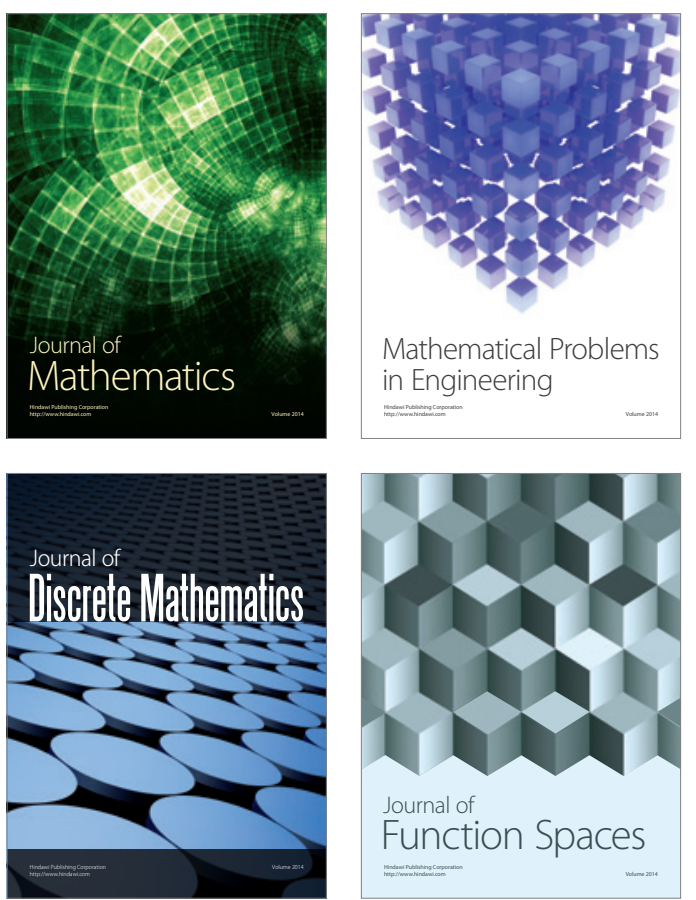

Mathematical Problems in Engineering
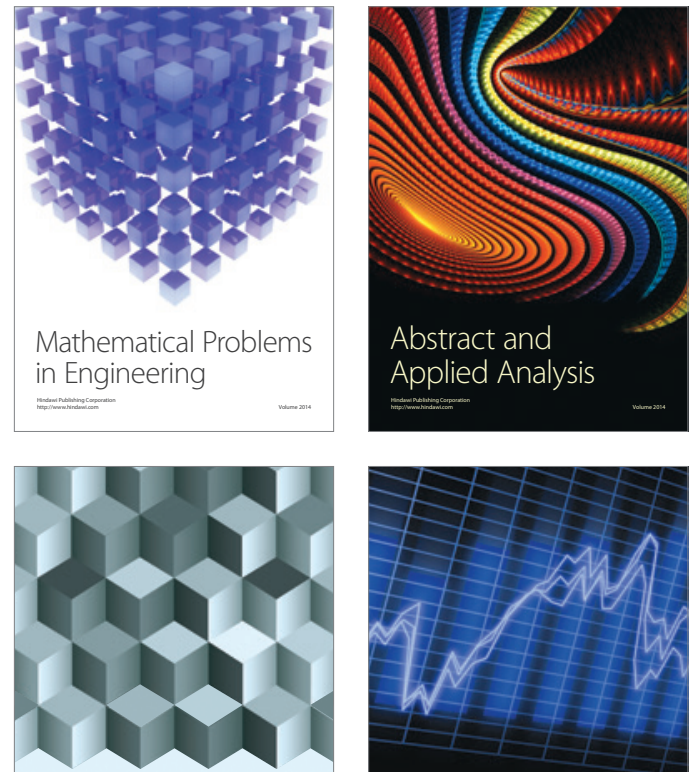

Journal of

Function Spaces

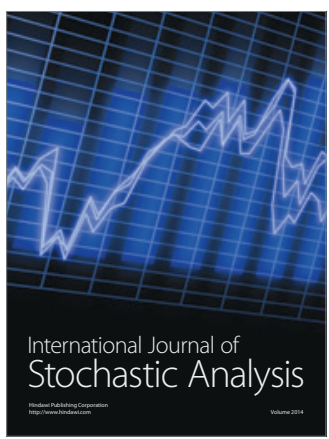

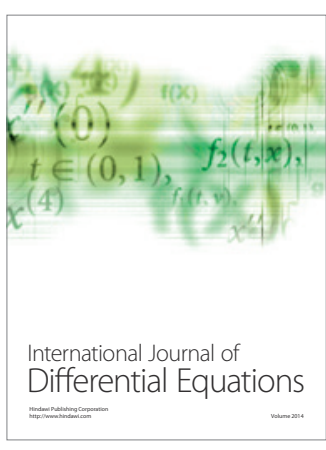
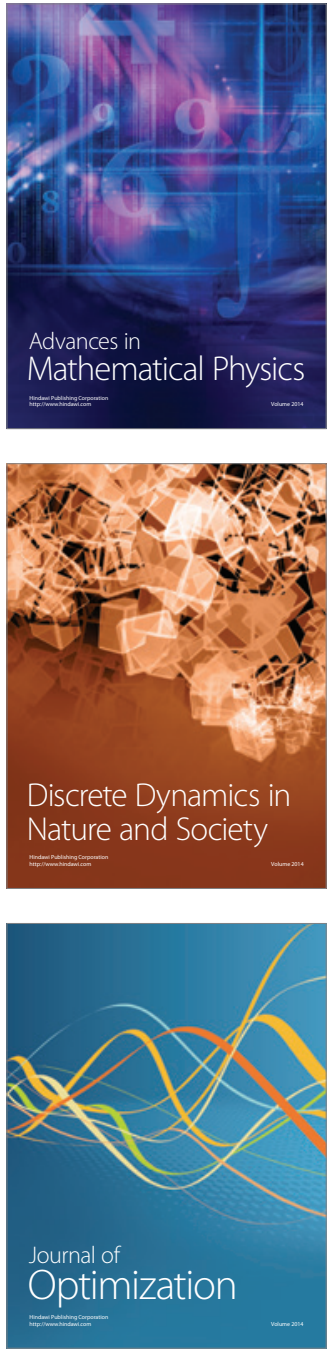